\title{
Response Patterns of Art Based Intervention for Self-Regulation among Athletes
}

\author{
Jolly Roy ${ }^{1}$, Garry Kuan ${ }^{2} \&$ Tneh Khai $\mathrm{Chy}^{3}$ \\ ${ }^{1}$ Sport Psychology Centre, National Sports Institute of Malaysia, Bukit Jalil, Malaysia \\ ${ }^{2}$ Exercise and Sports Science Programme, School of Health Sciences, Universiti Sains Malaysia, Kubang Kerian, \\ Kelantan, Malaysia \\ ${ }^{3}$ Penang Satellite Centre, National Sports Institute of Malaysia, Penang, Malaysia \\ Correspondence: Jolly Roy, Sport Psychology Centre, National Sports Institute of Malaysia, Bukit Jalil, 57000, \\ Kualalumpur, Malaysia. E-mail: jollyisn@gmail.com
}

Received: June 30, 2016

Accepted: July 14, $2016 \quad$ Online Published: August 11, 2016

doi:10.5539/ijps.v8n3p215

URL: http://dx.doi.org/10.5539/ijps.v8n3p215

\begin{abstract}
Competition outcome often shows a player's ability to self-regulate and be in control. This study examined the response patterns of Clay Button Method (CBM), an adapted art approach, in a sport context, among Paralympics, footballers and injured athletes for self-regulation. The article enlists the steps involved in CBM and the percentage of change is noted across six sessions among the participants. CBM focuses on teaching self-regulation by identifying individual areas of strengths and areas of concern, to build personal resources and weed out possible deficits. The participants engaged in CBM using playing clay, making their own self-image and exploring any unresolved emotional issues and bringing in desired changes. The response patterns revealed a trend where the players were able to self-regulate by reducing unproductive thoughts and strengthening personal resources. The study provides preliminary findings for introducing innovative approach in a sport context.
\end{abstract}

Keywords: art based intervention, self-regulation, clay button method, psychological skill training

\section{Introduction}

In preparing a player, self-regulation becomes centrally important because the drive to succeed and an inability to cope with the demand can cause stress and reduce well-being (Gould \& Whitley, 2009). In addition, reduced self-regulation can eventually result in burnout (Goodger \& Jones, 2012). Self-regulation to manage thoughts, feelings, and behavior plays a major role in human behavior and performance (Baumeister, 2002; Gailliot \& Baumeister, 2007). Researchers have demonstrated that self-regulation enhances the ability to plan ones behavior, reflect, and use logical reasoning but a reduction in the ability to self-regulate can impair performance in the executive functioning (Schmeichel, Vohs, \& Baumeister, 2003). In a sport context, the crucial role of self-regulation and its association with performance in sport is highlighted. The link between sport performance and one's thoughts, feelings and behaviours are documented by many researchers in the sport psychology domain (See Baumeister, Vohs, \& Tice, 2007; Dubuc-Charbonneau \& Durand-Bush, 2015; Gould, Dieffenbach, \& Moffett, 2002; Gould, Eklund, \& Jackson, 1992a, 1992b; MacNamara, Button, \& Collins, 2010a, 2010b). In sport, inappropriate self-regulation is reflected in errors of skill execution, decision-making and interpersonal conflicts (Collins \& Durand-Bush, 2014). Research findings have highlighted the importance and effectiveness of self-regulation in performance enhancement (See Callary \& Durand-Bush, 2008; Cleary \& Zimmerman, 2001; Collins \& Durand-Bush, 2010; Gould \& Udry, 1994; Kirschenbaum, 1984). When athletes compete, they experience stress in different intensities, which can impair optimal functioning leading to inconsistencies in performance. These stresses could be associated with performance outcome and its' meaning to the athlete or even result from players' internal conflicts.

There are numerous psychological skills (see Weinberg \& Williams, 2010) that can help an athlete to build up personal coping resources to facilitate self-regulation. Given a wide range of psychological skills, which is routinely taught to the athletes, it was thought appropriate to bring in an innovative approach for training self-regulation in an applied context. Deviating from traditional methods followed in the sports context, we considered a relatively new approach in line with art therapies and modified it to suit the sports context. 
We assumed that innovative measures would help to break the monotony of traditional approaches and we introduced the Clay Button Method (CBM). CBM makes an athlete mindful of the individual areas of concerns, teaches a player to be free of compulsion, and helps to change or modify psychological state responding to a context. In CBM, we use the playing clay material for the construction and deconstruction of the self-image. Playing clay is a familiar material used in art therapy in psychiatric and counseling settings, but it is not very commonly used in the sports context. We adapted the ideas of art based intervention to enable athletes to express freely the areas of strengths and areas of concern. The value of clay as a therapeutic material is documented in the literature (see Anderson, 1995; Mattes \& Robbins, 1981; Sholt \& Gavron, 2006) and the effects of CBM in the sports context were introduced in the literature (see Roy \& Nizar, 2009; Roy \& Kuan, 2016). A clay product can be touched and examined which has a crucial impact on how an individual represent their inner feeling (Sholt \& Gavron, 2006). The central aim of art method is to help players to go through the construction and deconstruction process of making their own self-image (clay buddy), creating awareness of what is underneath their mind and bring this to conscious expressions, by placing the clay buttons on the buddy. Clay buttons made from the red playing dove was chosen to represent the areas of concern and the areas of strengths were represented by any colour chosen by the athlete other than red. We considered what "color in context theory" predicted where red color is associated with a threat in achievement contexts (Elliot \& Maier, 2007, 2012; Moller, Elliot, \& Maier, 2009). In addition, the red color is often used to indicate errors in any evaluation situation, and more generally to signal any kind of warning signs (Allen \& Jones, 2014). The red color is also sometimes interpreted as a signal of danger (Moller et al., 2009).

The present study examined the response patterns of art based intervention while engaging in self-regulation of thoughts. We wanted to examine if the response pattern trends showed a reduction the areas of concern and enhance the areas of strength.

\section{Method}

\subsection{Participants}

This study employed a purposive sampling method. Access was gained to the athletes during the lead author's psychology sessions. We involved three different levels of athletes (a) paralympic powerlifting senior athletes $(\mathrm{n}=3)$ who represented in Olympics, (b) able bodied junior footballers $(\mathrm{n}=14)$ who is a back up squad for the in South East Asian Games, and (c) injured netball athletes engaged in international competitions $(\mathrm{n}=2)$.

Paralympic power lifters were involved in a pilot work to initially examine what kind of response patterns would emerge. The paralympic power lifters were older (mean age $=49.6$ years) and had been involved in the international competition for more than 10 years. The footballers were under 19 years team. Only those footballers who had attended all the intervention sessions were considered for data analysis. Injured netball athlete's mean age was 18 years and were in the national training camp. The netball players had international experience in competitions. Different levels of age, gender and sport were considered to identify how the new intervention protocol was received and to observe the similarity in the response patterns.

\subsection{Procedure}

The study is a part of applied research based practices approved by the National Institute of Sports. The study took place across 6 sessions within 3 months. Data collection was conducted by the lead researcher. The clay button intervention protocol provided here was developed by the researchers for use in sport context. The protocol integrates aspects of imagination, construction/ deconstruction process with clay and mindful changes.

Step 1: The athletes were asked to close the eyes and be mindful of their own image.

Step 2: The athletes were provided with the playing dove (approximately 250 grams) to create a self image (clay buddy), a few red clay buttons 2-3 millimeter in diameter and a few other color clay buttons of similar size.

Step 3: The athletes had to close their eyes, imagine a context (e.g., training/competition/rehabilitation) and execute an activity in the mind, to create awareness of areas of strengths and areas of concerns. Following this, the athletes had to place the clay buttons on the individual buddy (The areas of concern were always marked with red clay button and areas of strengths were marked with the personal choice of clay color). The number of red buttons and other color buttons were noted.

Step 4: The athletes were mindful of the change they desired and communicated silently with their buddy (self-regulation).The athletes then mentally effected the desired changes in the light of new insights.

Step 5: The athletes were required to add or remove the clay buttons on the clay buddy based on the new experience. The changes in the number of clay buttons placed (or removed) were noted. 


\section{Results}

The results (Figure 1) from the three paralympic athletes show a reduction in the red colour button and increase in other colour button across six sections (one athlete participated only in five sessions). During the initial testing with the paralympic group we only did the placing of the button once to see the response patterns. Step four was introduced after the pilot testing so that the desired change could be effected in the same session.
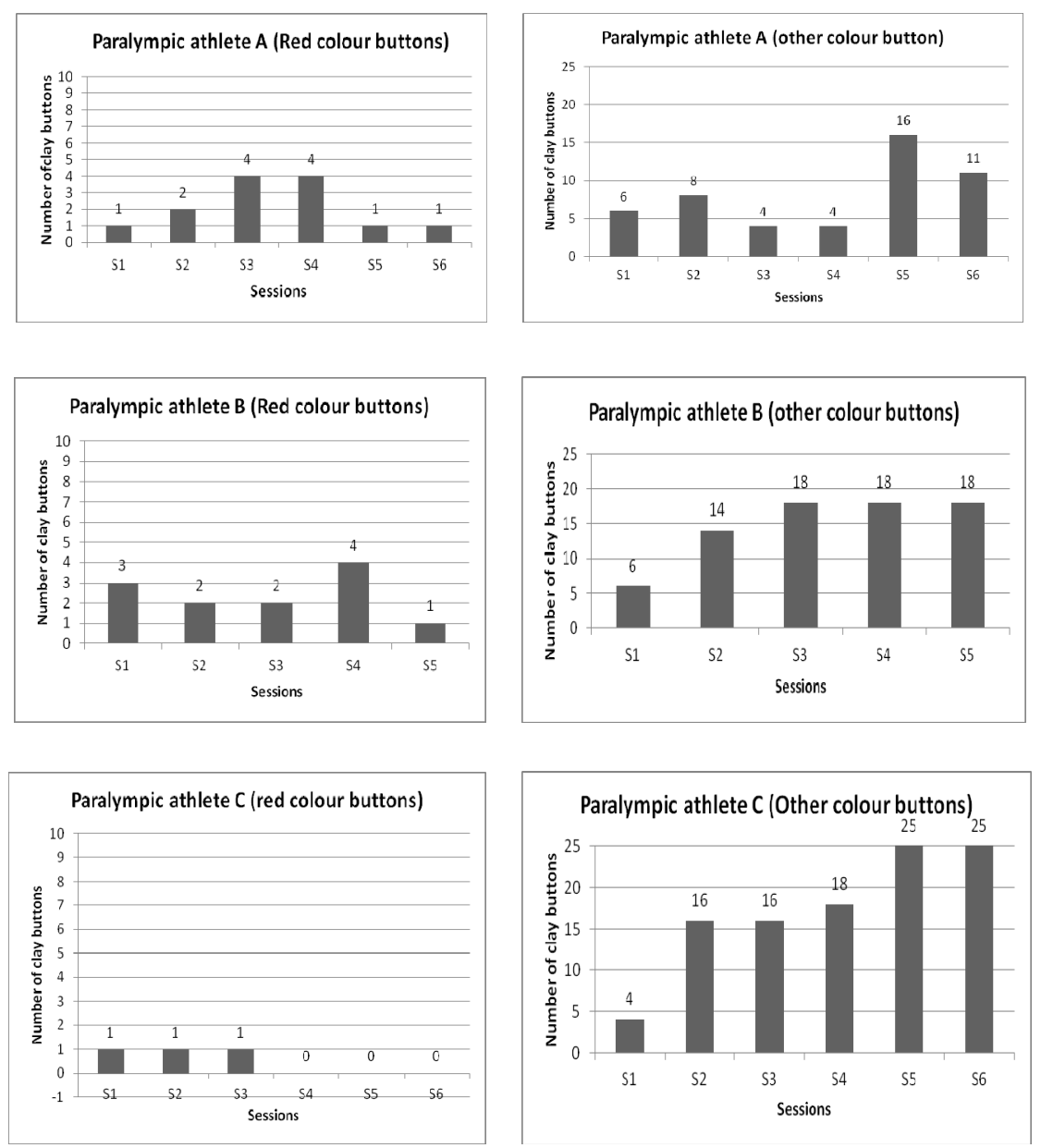

Figure 1. Response patterns from three paralympic power lifting athletes across six sessions

Fourteen footballers were monitored across six weeks and the responses are reported in percentage (number of athletes who reported increase/decrease or no change) of the red or other colored buttons (Figure 2 and 3). Considering the areas of concern, as expected, the results in the first three sessions, showed a decrease in the red colored button after intervention $(93 \%, 86 \%, \& 93 \%$ respectively) indicating that the footballers were able to self-regulate and mentally remove their concerns. In session four and five, the percentage of footballers showing decrease in red colour button was lesser $(57 \%, 57 \%$ respectively) but in the sixth session it again showed an improvement (71\%). In the first three sessions, the percentage of no change were less than $15 \%$, however, in session 4 and 5 , around $43 \%$ of the participants did not show any change in the red color button. In the sixth session, $71 \%$ of the participants reported a reduction in the number of the red colored button. 


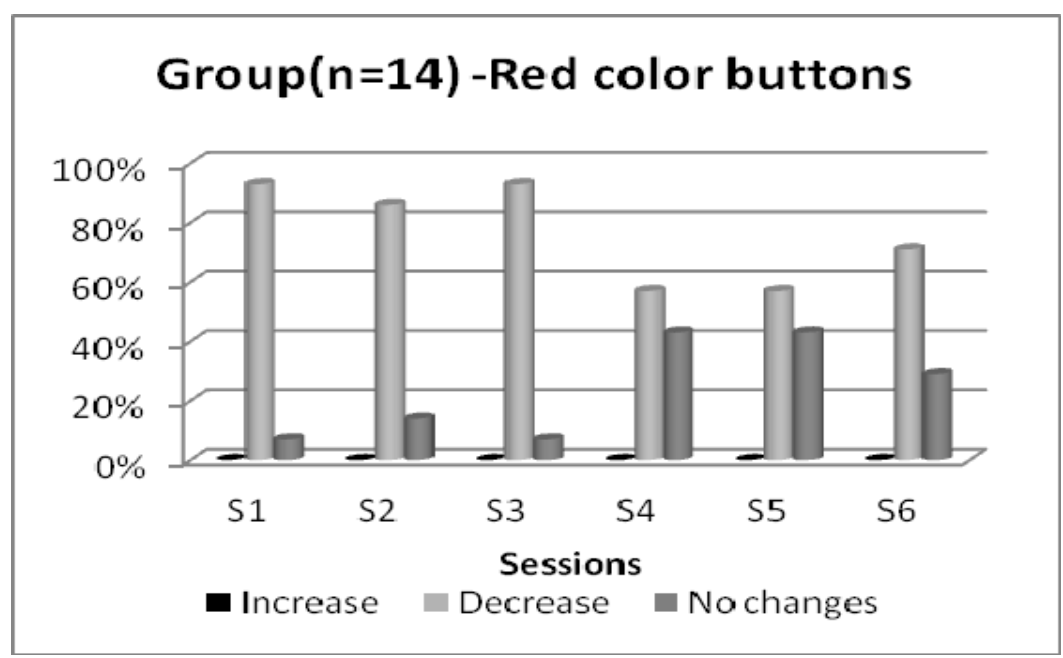

Figure 2. Response patterns in the in red color buttons (areas of concern)

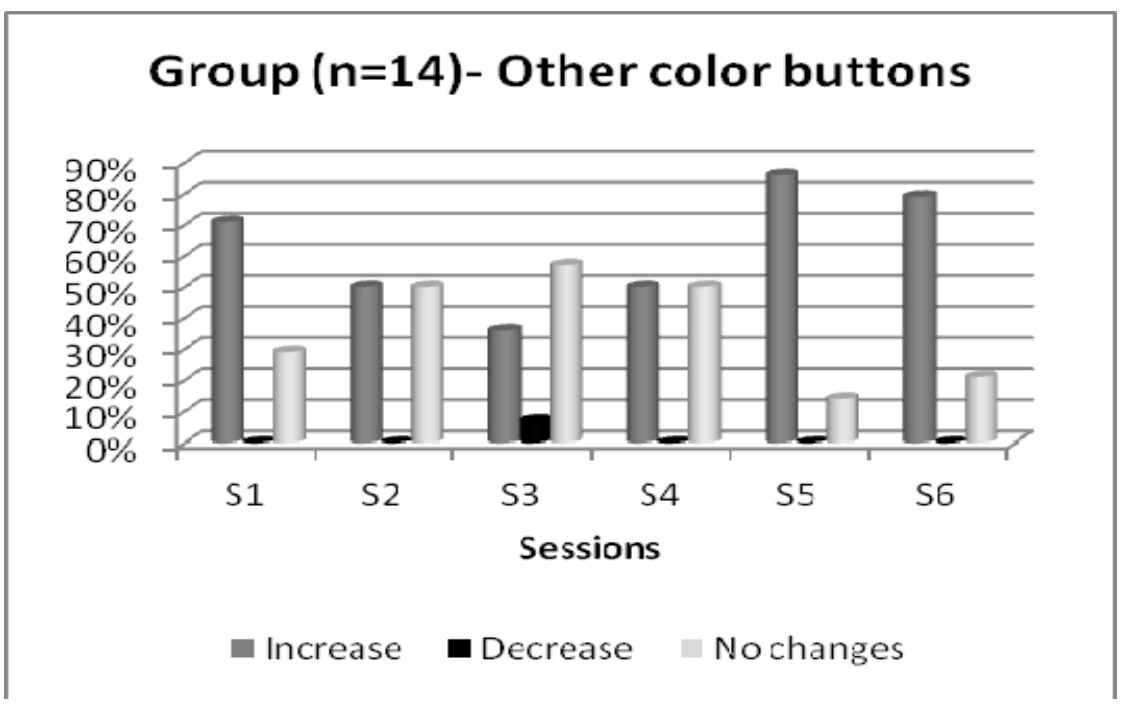

Figure 3. Response patterns in other color buttons (areas of strength)

In the case of other color buttons, signifying the areas of strength, in the initial session $71 \%$ participants showed an increase but in subsequent sessions (two, three and four) the percentage of athletes who showed the increase were lesser. A higher percentage of participants $(50 \% \& 57 \%)$ reported no change. Only in session three, $71 \%$ of participants showed a decrease in the areas of strength. In session five and six, $86 \%$ and $79 \%$ respectively showed increase and number of participants with no change were $14 \%$ and $21 \%$.

We present the results from three individual footballers to illustrate the changes across six sessions. Athlete A and $\mathrm{B}$ has shown definite changes and Athlete $\mathrm{C}$ has shown the decrease in the areas of concerns in the initial sessions and maintained throughout the remaining sessions (Figure 4). Figure 4 also illustrates the increase in other color buttons representing strengths. The visual analysis method helps the reader to visually inspect the data and interpret the outcome of the art based intervention. The graphical approach with single cases makes this data analysis meaningful and self-explanatory (Barker, McCarthy, Jones, \& Moran, 2011). 

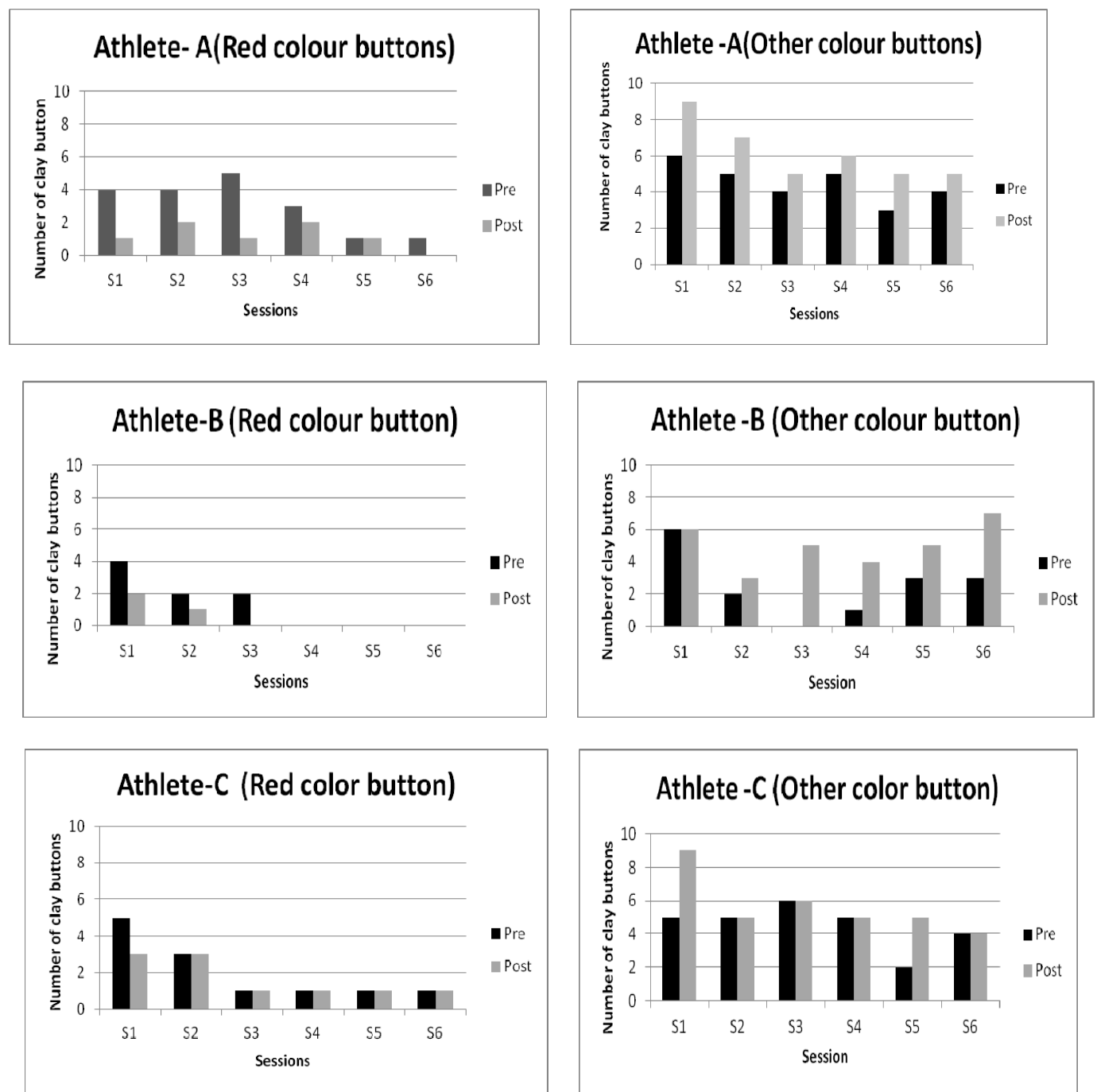

Figure 4. Response patterns from three individual footballers across six sessions (example)

Evidence from the responses of the patterns emerging from the injured athlete also show a reduction in red colour button across all the six sessions and increase in other colour buttons (Figure 5). Understanding the cognitive and emotional responses is important for facilitating rehabilitation behaviours.
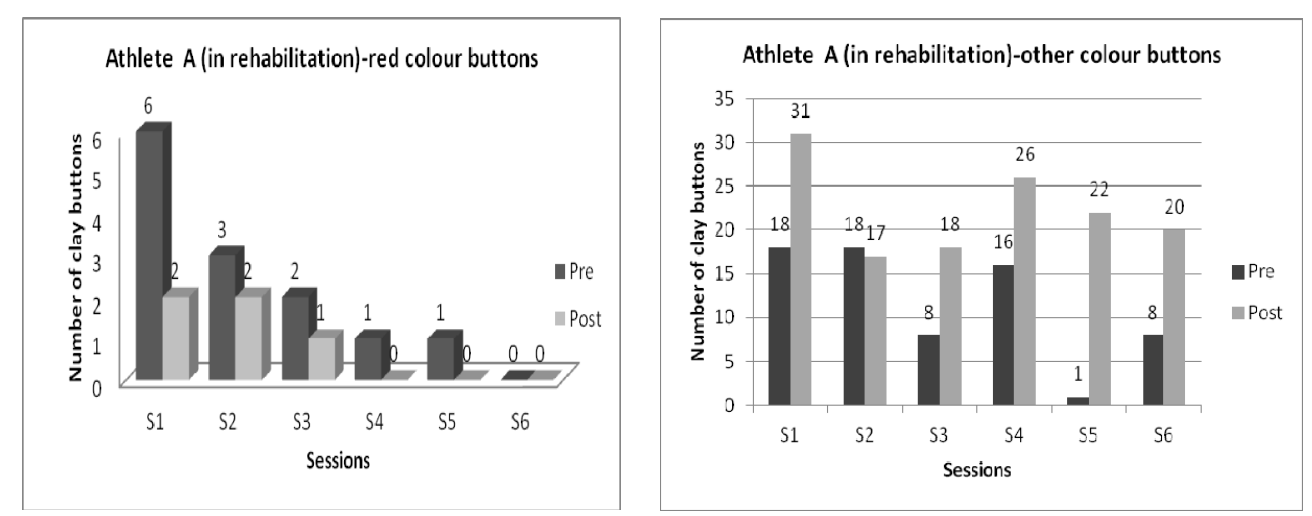

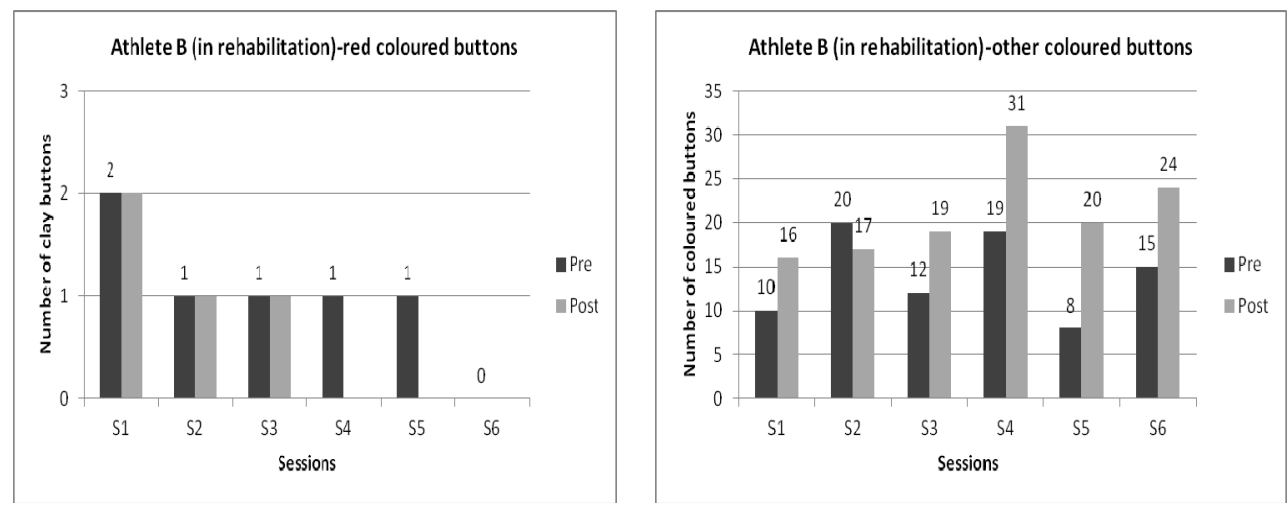

Figure 5. Response patterns from injured athletes across six sessions

\section{Discussion}

The present study sought to examine the response patterns of athletes while engaged in clay button method. The main aim was to introduce an art based approach and examine the response patterns in different athletes. At the first instance, there were a considerable percentage of footballers who reported a decrease in the red colour button indicating the conscious effort in self-regulation. The changes are also noted in the areas of strength with an increase of other color buttons. This response trends suggested that the art intervention is helping athletes' thought process and the clay is probably acting as a prop to facilitate this regulation.

Football is a team sport, however, regulation is emphasized at an individual level also for effective communication to make quick appropriate decision. To achieve this, an athlete should be devoid of internal conflicts and self-reflection is a key component, which is essential for self-regulation process (Zimmerman, 2002). Clay work involves powerful tactile expression and makes possible non-verbal communication for the creator to express oneself (Sholt \& Gavron, 2006). Clay has the capacity to be done and undone multiple times which helps an athlete in the construction and deconstruction process. Self-regulation enables any individual to control emotion, direct thoughts and attention (Sun \& Wu, 2011). In football, many factors affect a player's performance and the final outcome of the game. Therefore, self-control has a crucial effect in decision making and the ability of individual players to self-regulate is key to achieve a desired state of mind. The best performance of an individual is often associated with being in one's optimal zone (Hanin, 2000). Therefore considering the domain of competitive performance, training the athletes to regulate is imperative. The fun-filled approach such as CBM ensures less mental energy expenditure on the task and makes an athlete to feel more open, confident and secure to express himself. Through CBM, the practitioner tries to unearth and help the footballer to deal with his concerns while simultaneously working on his strengths to help the football player to move forward mindful of the concerns. In other words, it is not only addressing the concerns of the football player, but also sensitizing him with his strength.

In the case of Paralympics also self-regulation a very important set of skill to deal with challenges in the competition. Suggestion to explore relatively untapped methodologies of self-regulation (Ntoumanis \& Cumming, 2016) are welcome in the applied field. CBM fits into this suggestion of an effort undertaken specially in heavy sports like power lifting.

The results from the injured contexts also show a positive trend in better emotional management across the rehabilitation period. It is important to note the practical significance of the study. The results show that CBM had positive effects on better emotional management where the athletes were consciously able to initiate any distress related to injury, which is evident from the reduction of red colour buttons. An increase in the other colour buttons ensures that the athlete feel more positive when they return to play. At a professional level or a national level, any injury that keeps an athlete out of the game impose financial burdens besides requiring replaced player's adjustments in the technical or tactical skills. In the light of this, any meaningful psychological intervention that helps to reduce emotional distress and enhance strengths is acceptable.

The responses of increase in the other colour clay buttons representing areas of strengths provide some evidence to this. 
The activity used in the construction and deconstruction of the clay buddy helps the athletes to delve deep into his thoughts and feelings with ease. With constant training and expectations to perform well, every athlete is likely to experience mental fatigue and difficulty in adapting, which can result in using incorrect strategies. Research has highlighted that failure by an athlete to adapt is associated with overtraining resulting in using wrong strategies (Tenenbaum, Jones, Kitsantas, Sacks, \& Berwick, 2003). Through CBM, the practitioner can evoke multi-sensory engagement especially involving visual and tactile modalities to initiate a change process within oneself towards regulation to prepare an athlete for better adaptation. Athletes with good self-regulation are cognitively, motivationally and behaviorally involved in their own learning and performance (Zimmerman, 1990). The implication is that, athletes can be trained using innovative measures such as CBM, which can facilitate self-regulation. Deviations from engaging in the traditional self-regulation methods (e.g., arousal control, relaxation methods, imagery, self-talk) is expected to help athletes to avoid monotony in learning self-regulatory skills. Unique to CBM method is the importance attributed to intrapersonal reflections and goals. In team sports athletes do not perform in isolation, but self-regulation is key to maintain composure and direct desirable interactions and behavior during competition. The regulatory thought modification done during CBM is believed to enhance self-regulation by bringing in positive expectancies. The construction and deconstruction process while making the self-image and engaging in clay button placement, helps the athletes to repeat desirable thoughts to make it personally meaningful (or repeat undesirable thoughts until it loses its meaning: for example, imagining a difficult thought floating away in air like a feather or on a paper in a river). The new thoughts are fully accepted with openness and the athlete is encouraged to move forward in a desirable direction. Through $\mathrm{CBM}$, the player experiences new learning and learn to be flexible in their focus in a given moment.

In any art therapy, a connection between a mental world and a material world is crucial which reflects the inner world (Sholt \& Gavron, 2006). CBM creates opportunities for expression of an athlete's inner self without any inhibitions, which are clearly observed in the reduction of red color button, and increase or no change, in other color buttons, as shown in the graph. The tactile mode while engaging in CBM not only elicits fun in doing the activity but also functions as an effective way of expressing oneself. It helps to delve into one's past and ventilate one's unconscious thoughts, feelings and emotions. Symbolically the clay buddy represents the footballers themselves or the way they perceives himself as a whole individual. The internal concerns, which is typically masked is unearthed while engaged in CBM to remove the mental blocks that restrain regulation and tranquility. Clay work facilitates expression of emotions which were inaccessible to athletes, particularly who are very defensive. Literature in the art therapy field documents clay figures as representing strong emotions (Brock, 1991; Keyes, 1984; Mattes \& Robbins, 1981; Mitchell, 1984).

\section{Applied Perspectives}

From the applied perspective, coaches often try to nurture the athletes' self-regulation during training but have considerably less influence during the actual performance. For instance, in football, the athletes must be able to regulate themselves, as the game requires quick transitions and appropriate decision making. In strength based sports like power lifting, stress-energy balance, concentration and determination is crucial. In injured athletes, coping with pain and pressure to return to play is critical. The involvement in CBM enhances self-reflections, which lead to autonomy for regulation resulting in increased motivation and persistence in adversity. CBM helped the football players to pay attention to individual thoughts, feelings and emotions, and instill responsibility in footballers to reinforce self-regulation. The non judgmental awareness can be cultivated in young footballers to broaden their awareness to a wider range of fun filled experiences, minimizing threat related thoughts and enhancing strength based thoughts. Additionally, engaging in CBM may also provide an avenue for recognizing ones strength to incorporate with other psychological strategies. Research is needed to expand on this method and explicitly examine the role of CBM alone and in combination with other approaches. In future, playing appropriate music while the player is engaged in CBM would confirm the influence of music while engaging in art methods to unearth underlying thoughts, feelings and emotions. Recently, scientific studies into the effects of music in sports and exercise contexts have reported modest benefits to the listeners (see Karageorghis \& Priest, 2012). Thus, by using the "right" music, it can enhance athletes' experience, leading to the enhancement of mood and flow. For example, the use of classical music can be beneficial when task involving concentration and the use of motivational music can be beneficial to improve mood (Kuan, 2015). To our knowledge, this is the first study to demonstrate the beneficial use of art based intervention in an applied sport context. The findings suggest that art based interventions may be a promising area to extend our research.

The present study is not without strengths and limitations. The strength of this study lies on the topic being explored. The majority of self-regulation studies in the sports context focus on the impact of specific strategies such as imagery, self-talk, or relaxation. Few studies have explored art-based methods in a sport context. Thus 
CBM can be considered as an innovative approach in sports context and the response patterns show support to positive changes. The findings of this study lays a foundation in creating awareness to all stakeholders (e.g., young athletes, olympic level athletes, injured athletes) about potential new approaches in the applied field.

The limitation is that the study is conducted in a laboratory setting and its effectiveness in the actual competition needs further examination. As such, results have to be interpreted with caution. One observation made during the CBM was that athletes tend to use more clay to emphasize their thoughts. For example, if an injured athlete feels more pain the athlete tend to use more volume of clay. Therefore, in future studies, it would be good to consider the volume of the clay button. Another issue that needs attention in future research is the duration of the observed effects of CBM. It remains to be explored how much duration each athlete takes in making the self-image, how many times they alter it and why? Whether different types of music may impact an athlete when he/she is engaged in making the clay buddy.

Qualitative data taken after each session in future studies would yield in-depth subjective experiences during the engagement in CBM and reveal how the athletes progressed across different sessions. This study was the first initiative to examine the response patterns in terms of quantitative measures of CBM.

\section{Conclusion}

In summary, the results of this study provide preliminary evidence on how to use innovative measures such as CBM and quantify it. The art based intervention help the players to learn self-regulation in an enjoyable way and better manage their thoughts, feelings and emotions during competition setting. This study can serve as a starting point for practitioners aiming to help athletes. The present study is an initial attempt to fill the gap of introducing art methods in self-regulation training by borrowing ideas from art therapy domain. Given the scarcity of art based intervention in sports context, more studies with different sports and playing levels are warranted.

\section{References}

Allen, M. S., \& Jones, M. V. (2014). The home advantage over the first 20 seasons of the English premier league: Effects of shirt color, team ability, and time trends. International Journal of Sport and Exercise Psychology, 12, 19-33. http://dx.doi.org/10.1080/1612197x.2012.756230

Anderson, F. E. (1995). Catharsis and empowerment through group clay work with incest survivors. The Arts in Psychotherapy, 22, 413-427. http://dx.doi.org/10.1016/0197-4556(94)00046-8

Barker, J., McCarthy, P., Jones, M., \& Moran, A. (2011). Single-Case Research Methods in Sport and Exercise Psychology (pp. 145-166). Routledge, USA.

Baumeister, R. F., Vohs, K. D., \& Tice, D. M. (2007). The strength model of self-control. Current Directions in Psychological Science, 16, 351-355. http://dx.doi.org/10.1111/j.1467-8721.2007.00534.x

Baumeister. (2002). Ego depletion and self-control failure: An energy model of the self's executive function. Self and Identity, 1, 129-136. http://dx.doi.org/10.1080/152988602317319302

Brock, M. (1991). The therapeutic use of clay. British Journal of Occupational Therapy, 54(1), 13-15. http://dx.doi.org/10.1177/030802269105400108

Callary, B., \& Durand-Bush, N. (2008). A group resonance intervention with a volleyball team: An exploration of the process between a consultant, coach, and athletes. Athletic Insight, 10. Retrieved December 15, 2015, from http://www.athleticinsight.com/Vol10Iss3/Groupprocess.htm

Cleary, T. J., \& Zimmerman, B. J. (2001). Self-regulation differences during athletic practice by experts, non-experts, and novices. Journal of Applied Sport Psychology, 13, 185-206. http://dx.doi.org/10.1080/104132001753149883

Collins, J., \& Durand-Bush, N. (2010). Case study: Enhancing the cohesion and performance of an elite curling team through a self-regulation intervention. International Journal of Sports Science and Coaching, 5, 343-362. http://dx.doi.org/10.1260/1747-9541.5.3.343

Collins, J., \& Durand-Bush, N. (2014). Strategies used by an elite curling coach to nurture athletes' self-regulation: A single case study. Journal of Applied Sport Psychology, 26, 211-225. http://dx.doi.org/10.1080/10413200.2013.819823

Dubuc-Charbonneau, N., \& Durand-Bush, N. (2015) Moving into action: The effects of a self-regulation intervention on the stress, burnout, well-being, and self-regulation capacity levels of university $\begin{array}{lllll}\text { student-athletes. Journal of Clinical Sport Psychology, } & \text { 9, } & \text { 173-192. }\end{array}$ http://dx.doi.org/10.1123/jcsp.2014-0036 
Elliot, A. J., \& Maier, M. A. (2007). Color and psychological functioning. Current Directions in Psychological Science, 16, 250-254. http://dx.doi.org/10.1111/j.1467-8721.2007.00514.x

Elliot, A. J., \& Maier, M. A. (2012). Color-in-context theory. In P. Devine, \& A. Plant (Eds.), Advances in Experimental Social Psychology (Vol. 45, pp. 61-125). Burlington VT: Academic Press. http://dx.doi.org/10.1016/b978-0-12-394286-9.00002-0

Gailliot, M. T., \& Baumeister, R. F. (2007). The physiology of will power: Linking blood glucose to self-control. Personality and Social Psychology Review, 11,303-327. http://dx.doi.org/10.1177/1088868307303030

Goodger, K., \& Jones, M. (2012). Burnout: A darker side to performance. In S. M. Murphy (Ed.), The Oxford Handbook of Sport and Performance Psychology (pp. 562-580). New York, NY: Oxford University press. http://dx.doi.org/10.1093/oxfordhb/9780199731763.013.0030

Gould, D. R. C., \& Jackson, S. A. (1992b). 1988 U.S. Olympic wrestling excellence: 11. Thoughts and affect occurring during competition. The Sport Psychologist, 6, 383-402.

Gould, D., \& Udry, E. (1994). Psychological skills for enhancing performance: Arousal regulation strategies.

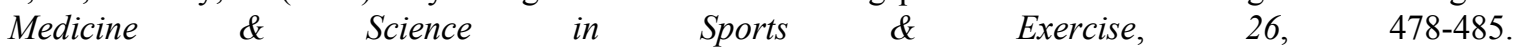
http://dx.doi.org/10.1249/00005768-199404000-00013

Gould, D., \& Whitley, M. A. (2009). Sources and consequences of athletic burnout among college athletes. Journal of Intercollegiate sports, 2, 16-30.

Gould, D., Dieffenbach, K., \& Moffett, A. (2002). Psychological characteristics and their development in Olympic champions. Journal of Applied Sport Psychology, 14, 172-204. http://dx.doi.org/10.1080/10413200290103482

Gould, D., Eklund, R. C., \& Jackson, S. A. (1992a). 1988 U.S. Olympic wrestling excellence: 1. Mental preparation, precompetitive cognition, and affect. The Sport Psychologist, 6, 358-382.

Hanin, Y. L. (2000). Emotions in sport. U.S.A, Human Kinetics.

Karageorghis, C. I., \& Priest, D. L. (2012). Music in the exercise domain: A review and synthesis (part 1). International Review of Sport \& Exercise Psychology, 5(1), 67-84. http://dx.doi.org/10.1080/1750984X.2011.631027

Keyes, M. F. (1984). The family clay sculpture in redecision therapy. Transactional Analysis journal, 14(1), 68-71.

Kirschenbaum, D. S. (1984). Self-regulation and sport psychology: Nurturing an emerging symbiosis. Journal of Sport Psychology, 6, 159-183.

Kuan, G. (2015). Using the right music when performing imagery training for excellence. In J. Mohan (Ed.), Excellence: A Multidimentional Appraisal (pp. 120-132). Punjab University Press, Chandigarh.

MacNamara, A., Button, A., \& Collins, D. (2010a). The role of psychological characteristics in facilitating the pathway to elite performance part1: Identifying mental skills and behaviors. The Sport Psychologist, 24, 52-73.

MacNamara, A., Button, A., \& Collins, D. (2010b). The role of psychological characteristics in facilitating the pathway to elite performance part 11: Examining environmental and stage-related differences in skill and behaviors. The Sport Psychologist, 24, 74-96.

Mattes, J., \& Robbins, A. (1981). Creative interventions in psychoanalytic psychotherapy. The Psychoanalytic Reviews, 68, 386-394.

Mitchell, P. (1984). The role of regression in treatment of depression with an intact ego. Pratt Institute Creative Arts Therapy Review, 5, 17-21.

Moller, A. C., Elliot, A. J., \& Maier, M. A. (2009). Basic hue-meaning associations. Emotion, 8, 898-902. http://dx.doi.org/10.1037/a0017811

Ntoumanis, N., \& Cumming, J. (2016). Self-regulation. In R. J. Schinke, K. R. Mc Gannon, \& B. Smith (Eds.), Routledge International Handbook of Sport Psychology (pp. 315-323). London and New York: Routledge, Taylor and Francis.

Roy, J., \& Kuan, G. (2016). Mood Measurement and Regulation in Applied Settings. In R. J. Schinke, K. R. Mc Gannon, \& B. Smith (Eds.), Routledge International Handbook of Sport Psychology (pp. 315-323). London and New York: Routledge, Taylor and Francis. 
Roy, J., \& Nizar, M. (2009). Babroy clay button technique in thought management among Paralympics. Poster presentation at $12^{\text {th }}$ ISSP World Congress of Sport Psychology, Marrakech, Morocco.

Schmeichel, B. J., Vohs, K. D., \& Baumeister, R. F. (2003). Intellectual performance and ego depletion: Role of the self in logical reasoning and other information processing. Journal of Personality and Social psychology, 85, 33-46. http://dx.doi.org/10.1037/0022-3514.85.1.33

Sholt, M., \& Gavron, T. (2006). Therapeutic qualities of clay-work in art therapy and psychotherapy: A review. Art Therapy: Journal of the American Art Therapy Association, 23, 66-72. $\mathrm{http}: / / \mathrm{dx}$. doi.org/10.1080/07421656.2006.10129647

Sun, Y., \& Wu, X. (2011). Self-regulation of elite athletes in China. Social behaviour and personality, 39, 1035-1044. http://dx.doi.org/10.2224/sbp.2011.39.8.1035

Tenenbaum, G., Jones, C. M., Kitsantas, A., Sacks, D. N., \& Berwick, J. P. (2003). Failure adaptation: An investigation of the stress response process in sport. International Journal of Sport Psychology, 34, 27-62.

Weinberg, R. S., \& Williams, J. M. (2010). Integrating and implementing a psychological skill training program. In J. M. William (Ed.), Applied Sport Psychology: Personal growth to peak performance (pp. 361-385). NY, Mc-Graw Hill.

Zimmerman, B. J. (1990). Self-regulated learning and academic achievement: An overview. Educational Psychologist, 25, 3-17. http://dx.doi.org/10.1207/s15326985ep2501_2

Zimmerman, B. J. (2002). Becoming a self-regulated learner: An overview. Theory into Practice, 41, 64-70. http://dx.doi.org/10.1207/s15430421tip4102_2

\section{Appendix}

Example of a clay buddy

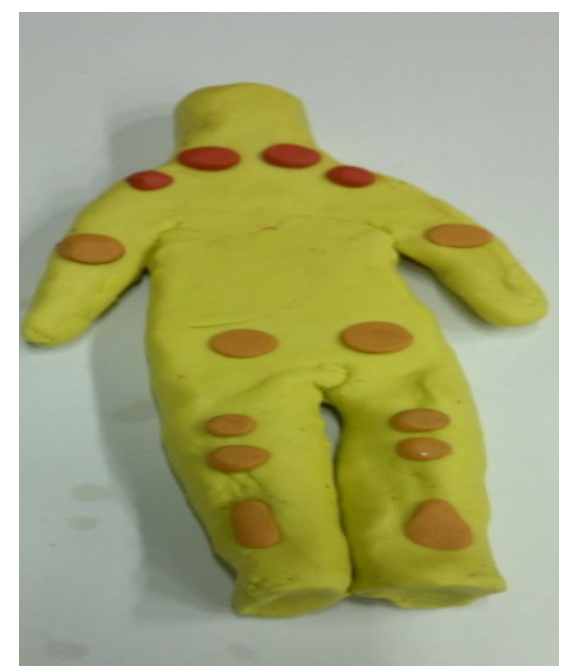




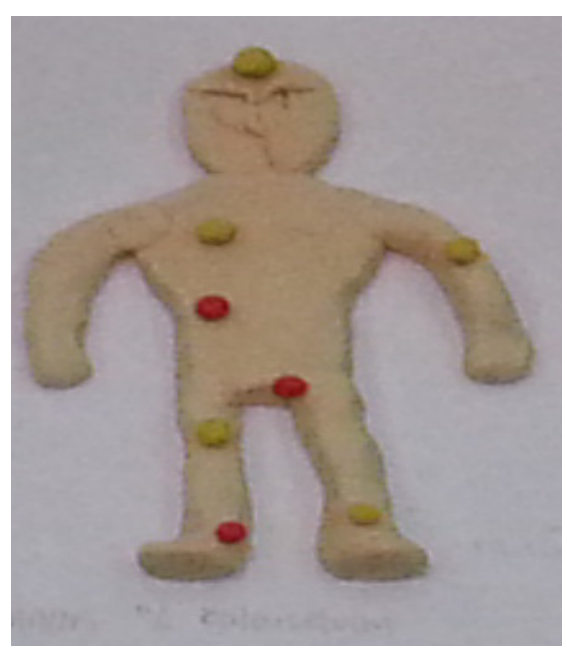

\section{Copyrights}

Copyright for this article is retained by the author(s), with first publication rights granted to the journal.

This is an open-access article distributed under the terms and conditions of the Creative Commons Attribution license (http://creativecommons.org/licenses/by/4.0/). 